\title{
Sintering Kinetics and Microstructure Development of Nanoscale Y-TZP Ceramics
}

\author{
G. S. A. M. Theunissen, ${ }^{*}$ A. J. A. Winnubst ${ }^{*} \&$ A. J. Burggraaf \\ University of Twente, Faculty of Chemical Technology, Laboratory for Inorganic Chemistry, \\ Materials Science and Catalysis, PO Box 217, 7500 AE Enschede, The Netherlands
}

(Received 22 April 1992; accepted 17 July 1992)

\begin{abstract}
Zirconia samples doped with 3 mol\% yttria were prepared by gel precipitation from a metal chloride solution and their sintering behaviour compared with that of a commercial powder. Dense (relative density. 97\%) nanoscale ceramics with a mean grain size of $60 \mathrm{~nm}$ are ohtained after sintering at $1050 \mathrm{C}$ for $7 \mathrm{~h}$. Important densification mechanisms in the initial sintering stage are grain boundary sliding and grain boundary diffusion. Grain grow th in the final sintering stage seems to be impurity drag controlled. Extremely low activation energies are obtained for both densification and grain growth in the initial sintering stages. Special attention has been paid to the effect of aggregate size of the precursor powder on the final grain size.
\end{abstract}

Zirkoniumdioxid-Proben, denen 3 Mol\% Yttriumoxid zugesetzt war, sind mittels Gel-Ausscheidung aus einer Metall-Chlorid-Lösung hergestellt worden. Das Sinterverhalten dieser Proben wurde mit dem handeIsüblicher Pulver verglichen. Dichte (relative Dichte: 97\%) nanokristalline Keramiken mit einer mittleren Korngrößße von $60 \mathrm{~nm}$ konnten nach 7-stündigem Sintern hei $1050^{\circ} \mathrm{C}$ hergestellt werden. Die wichtigsten Verdichtungsmechanismen in den anfänglichen Stadien des Sinterns sind Korngrenzengleiten und Korngrenzendiffiusion. Das Kornwachstum während der Endphase des Sintervorgangs scheint durch 'impurity-drag' kontrolliert zu sein. Sowohl für die Verdichtung als auch für das Kornwachstum werden sehr geringe Aktivierungsenergien während der angfänglichen Phasen des Sinterns beobachtet. Besondere Aufmerksamkeit wurde dem Effekt der

* Present address: Philips Research, PO Box 80.000, 5600 JA Eindhoven, The Netherlands.

¥To whom correspondence should be addressed.
Aggregatgröße der Prekursor-Pulver auf die Endkorngröße der Keramik zugewandt.

Des échantillons en zircone dopée avec $3 \mathrm{~mol} \%$ d'oxyde d'yttrium ont été préparés par précipitation d'un gel au départ d'une solution de chlorures métalliques. Leur comportement au frittage a été comparé à celui d'une poudre commerciale. Des céramiques denses (densité relative 97\%) de taille nanométrique avec une taille de grain movenne de $60 \mathrm{~nm}$ sont obtenues par frittage à $1050^{\circ} \mathrm{C}$ pendant $7 \mathrm{~h}$. Les mécanismes de densification prépondérants dans le stade initial du frittage sont le glissement des joints de grains et la diffusion aux joints de grains. Il semble que la croissance cristalline à la fin du frittage est contrôlée par la ségrégation des impuretés. Des énergies d'activation extrêmement basses sont obtenues tant pour la densification que pour la croissance cristalline dans les stades initiaux du frittage. Une attention particulière a été apportée à l'effet de la taille des agrégats de poudre de précurseur sur la taille finale des grains.

\section{Introduction}

Polycrystalline $100 \%$ tetragonal $\mathrm{ZrO}_{2}-\mathrm{Y}_{2} \mathrm{O}_{3}$ ceramics (Y-TZP) are regarded as materials exhibiting high strength and toughness. ${ }^{1}$ In order to obtain a fully stabilized tetragonal structure at room temperature the grain size must be less than $0 \cdot 8 \mu \mathrm{m}$ in the case of a $3 \mathrm{~mol} \% \quad \mathrm{Y}_{2} \mathrm{O}_{3}$-doped $\mathrm{ZrO}_{2}$ ceramic. $^{2}$ This critical grain size is reduced drastically when Y-TZP is exposed to humid atmospheres at elevated temperatures. ${ }^{3,4}$ In this case the grain size of $3 \mathrm{~mol} \% \mathrm{Y}_{2} \mathrm{O}_{3}-$ $\mathrm{ZrO}_{2}$ must be less than $0.25 \mu \mathrm{m} .{ }^{3}$ In the past, dense cubic $\mathrm{ZrO}_{2}-\mathrm{Y}_{2} \mathrm{O}_{3}$ ceramics with a small grain size $(0.4 \mu \mathrm{m})$ were obtained at relatively low sintering temperatures when (ultra)fine-grained, weakly 
agglomerated powders (primary crystallite size $8 \mathrm{~nm}$ ) were used as starting material. ${ }^{5}$ Often these powders are prepared by means of wet chemical synthesis methods, e.g. gel-precipitation techniques. $^{5-9}$ In order to prevent the formation of strong agglomerates between these fine crystallites the precipitated gels have to be treated in such a way that a minimal degree of cross-linking is obtained. ${ }^{7-11}$ The state of agglomeration influences the pore size distribution within powder compacts during pressing and therefore also the sintering behaviour of the compacts. It is known ${ }^{12.13}$ that aggregates and agglomerates, if present in a compact, densify more rapidly than the surrounding matrix and therefore can give rise to cracks and large stresses which cannot be removed during sintering. The smaller the agglomerates or the aggregates are, the smaller the remaining defects will be. It is therefore likely that these detrimental effects can be minimized in nanoscale ceramics. The microstructure development during compaction has been studied extensively by a number of authors. ${ }^{5,8.14}$ The powders studied in these papers differ in primary crystallite size, agglomerate density and the way the agglomerates can be fractured. For cubic materials it has been shown that (i) at low temperatures $\left(900^{\circ} \mathrm{C}\right)$ the aggregates are converted to crystallites which are larger than the primary crystallites and (ii) densification and grain growth proceed in several stages. ${ }^{5}$ This points to the considerable potential of reducing the final grain size by reduction of the aggregate size. It is possible that nanoscale ceramics might be obtained in this way.

Ceramics with a grain size in the nanoscale range have great potential. Besides the reasons already mentioned, a small grain size can be very interesting for several other reasons. In the first place it is favourable for obtaining (super)plastic deformation. The deformation rate is proportional to the inverse or the inverse square of the grain diameter, depending on the kind of deformation mechanism. ${ }^{15}$ Decreasing the grain size to nanoscale levels can increase drastically both the deformation rate and the total strain in hot forging operations, while the size of the defects is decreased. Furthermore, nanoscale ceramics are a good start for postsintering heat treatments. Then the grains in the final structure can be grown to any desired size, provided the grain growth can be controlled. This means that normal or retarded grain growth is necessary. In this way the thermal and chemical stability and the hightemperature mechanical properties can be affected. Preliminary results of the latter are given by Theunissen et al. ${ }^{16}$

In this paper the microstructure development of (ultra)fine-grained Y-TZP powders during the sintering process is investigated in order to obtain nanoscale, dense ceramics. The sintering behaviour is compared with that of a commercial powder.

\section{Experimental Procedure}

Y-TZP powders doped with $5.8 \mathrm{~mol} \% \mathrm{YO}_{1.5}$ (denoted as $Z Y x$, with $x$ at. $\%$ Y) were prepared by gel precipitation. ${ }^{8}$ This involves the hydrolysis of a diluted solution of metal chlorides in an excess of a $25 \mathrm{wt} \%$ ammonia solution (the 'chloride' method). After hydrolysis the gel was thoroughly washed with a water/ammonia mixture in order to remove the chlorides ${ }^{78.17}$ and subsequently with ethanol to remove free water. Both the precipitation and washing steps were performed in a baffled vessel reactor of the type described by van de Graaf et al. ${ }^{5}$ The reactor was equipped with a dispersion turbine during precipitation and with a high-energy disc turbine during washing. This promotes a high degree of dispersion, large local $\mathrm{H}_{2} \mathrm{O}$ excess and consequently a 'nucleation burst', resulting in small crystallites. The gel was dried in air for $15 \mathrm{~h}\left(120^{\circ} \mathrm{C}\right)$ and calcined at $550^{\circ} \mathrm{C}$ for $2 \mathrm{~h}$. The sintering behaviour of this 'chloride' powder was compared with a commercial Y-TZP 'Tosoh' powder (TZ3Y, Tosoh Manufacturing Co. Ltd, Tokyo, Japan) with the same chemical composition. X-Ray fluorescence spectrometry, using a Philips PW 1410 spectrometer, was used for the analysis of overall composition. Powders were isostatically pressed at $400 \mathrm{MPa}$. Both grain growth and densification were analysed during sintering. The samples were sintered in air in a Vecstar furnace or a Netzsch 402E dilatometer at a heating rate of $2^{\circ} \mathrm{C} / \mathrm{min}$. The isothermally sintered specimens were heated to $900^{\circ} \mathrm{C}$ at a heating rate of $2 \mathrm{C} / \mathrm{min}$, held at this temperature for $5 \mathrm{~h}$ and subsequently heated to the final sintering temperature at a heating rate of $1^{\circ} \mathrm{C} / \mathrm{min}$. After sintering in this way the samples were quenched to room temperature to prevent any further grain growth. For the kinetic analysis the actual densities and grain sizes after reaching the sintering temperature were used as the initial state. Densities were measured by Archimedes' method in $\mathrm{Hg}$.

Nitrogen adsorption and desorption isotherms were measured at $77 \mathrm{~K}$ using a Micromeritics ASAP 2400. Pore size distributions and pore volumes were calculated from the desorption and adsorption branches of the hysteresis loops according to the method described by Dollimore \& Heal. ${ }^{18}$ Pores with radii larger than about $15 \mathrm{~nm}$ were determined by mercury intrusion porosimetry with a Carlo Erba Porosimeter (Series 200) at pressures up to $200 \mathrm{MPa}$. Grain sizes $<70 \mathrm{~nm}$ were determined by means of $X$ ray line broadening measurements ${ }^{19}$ using a Philips $\mathrm{X}$-ray diffractometer (PW 1370) with $\mathrm{Cu} K_{x}$ radi- 


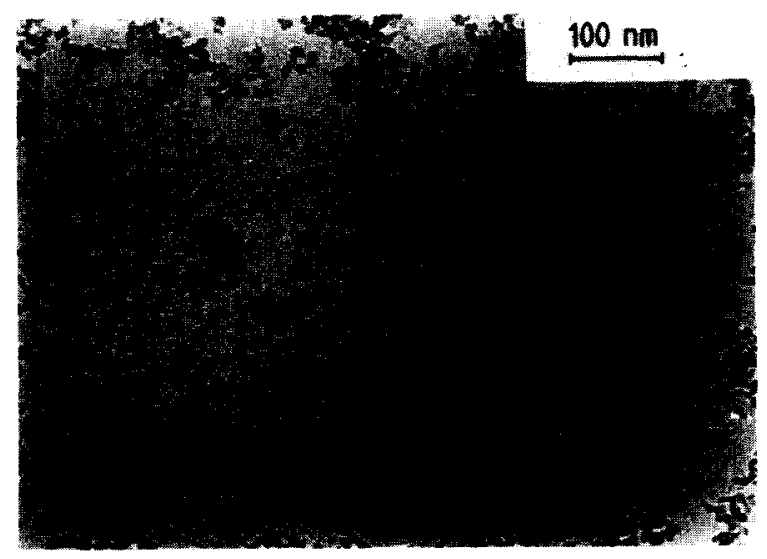

Fig. 1. TEM micrograph of a calcined ZY 5.8 chloride powder.

ation. The crystallite diameter $(D)$ was calculated from the (111) reflection of the tetragonal phase using the Scherrer relationship: ${ }^{19}$

$$
D=\frac{K \lambda}{\beta \cos \theta}
$$

where $\beta$ is the integral linewidth, $\lambda$ the wavelength of the radiation used $\left(\mathrm{Cu} K_{x}\right), K$ a constant set to unity and $\theta$ the diffraction angle. The peaks were corrected for $K_{x_{1}}-K_{x_{2}}$ separation and instrumental broadening assuming a Cauchy relationship and microstrain assuming a Gauss relationship. A Jeol 200CT transmission electron microscope (TEM) was used for direct observations of grain sizes $<70 \mathrm{~nm}$, whereas a Hitachi S-600 scanning electron microscope (SEM) was used on polished surfaces for grain sizes $>70 \mathrm{~nm}$. A volume-averaged grain size was calculated by the method of $\mathrm{Oel}^{20}$ using more than 300 grains for each measurement.

\section{Results and Discussion}

\subsection{Powder characteristics}

The composition of the powders used was in all cases ZY 5.8. Some of the powder properties are listed in Table 1. The microstructure development during compaction is explained in detail by Groot Zevert et $a l^{8}$ and in Ref. 21. In Ref. 21 it was concluded that the chloride powder consisted of small chains of crystallites creating small aggregates $(15-16 \mathrm{~nm})$ at the intersections of the chains. These aggregates

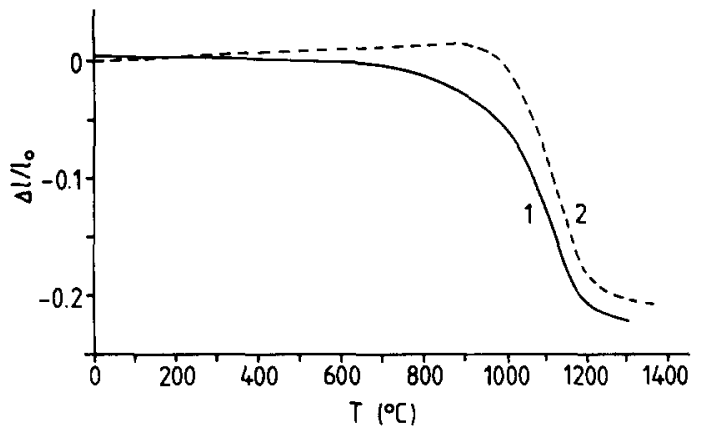

(a)

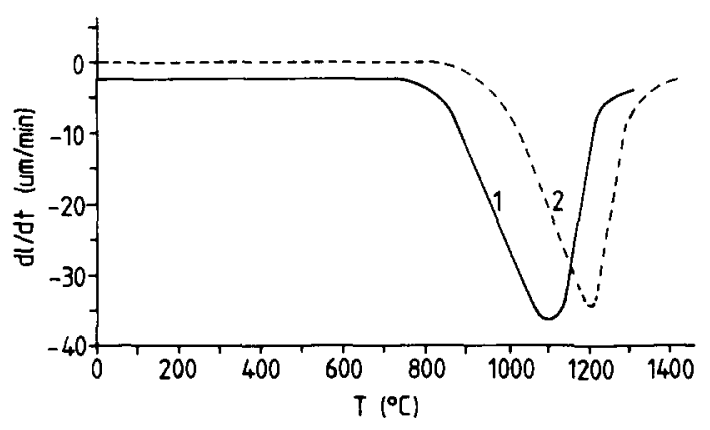

(b)

Fig. 2. (a) Dilatometer curve of a ZY 5.8 chloride compact (1) and Tosoh compact (2); (b) densification rates. Heating rate $2^{\circ} \mathrm{C} / \mathrm{min}$.

consisted of about 5-6 primary crystallites which were $8 \mathrm{~nm}$ in size (Fig. 1). The Tosoh powder contained large dense aggregates which were about $50 \mathrm{~nm}$ in size. ${ }^{21,22}$ After compaction at $400 \mathrm{MPa}$ both powder compacts mainly consist of regular stacked aggregates.

\subsection{Non-isothermal densification}

In Fig. 2(a) the dilatometer curves during nonisothermal sintering of the chloride and Tosoh compacts are given. It is obvious that they show a different densification behaviour. The densification behaviour of the chloride powder seems to be the better $(96 \%$ of the theoretical density reached at $1150^{\circ} \mathrm{C}$ ). At about $1250^{\circ} \mathrm{C}$ it is possible to densify both the chloride and Tosoh powder to more than $98 \%$ of the theoretical density. Figure 2 (b) shows the densification rates during sintering. The maximum in densification rate is found at 1090 and $1200^{\circ} \mathrm{C}$ for the chloride and Tosoh compact, respectively. This proves the better sinterability of the chloride compact compared with the Tosoh compact. Sec-

Table 1. Powder properties

\begin{tabular}{lccccc} 
Synthesis & $\begin{array}{c}\text { Agglomerate } \\
\text { strength } \\
(\mathrm{MPa})\end{array}$ & $\begin{array}{c}\text { Agglomerate } \\
\text { density } \\
(\%)\end{array}$ & $\begin{array}{c}S_{\mathrm{BET}} \\
\left(\mathrm{m}^{2} / g\right)\end{array}$ & $\begin{array}{c}D(X R L B) \\
(\mathrm{nm})\end{array}$ & $\begin{array}{c}T D^{a} \\
(\%)\end{array}$ \\
\hline Chloride & 80 & 30 & 125 & 8 & 19 \\
Tosoh & 40 & 36 & 21 & 34 & 22 \\
\hline
\end{tabular}

${ }^{a} \mathrm{TD}=$ tap density; powder density after vibrating a test tube with powder until the powder volume remained constant. 


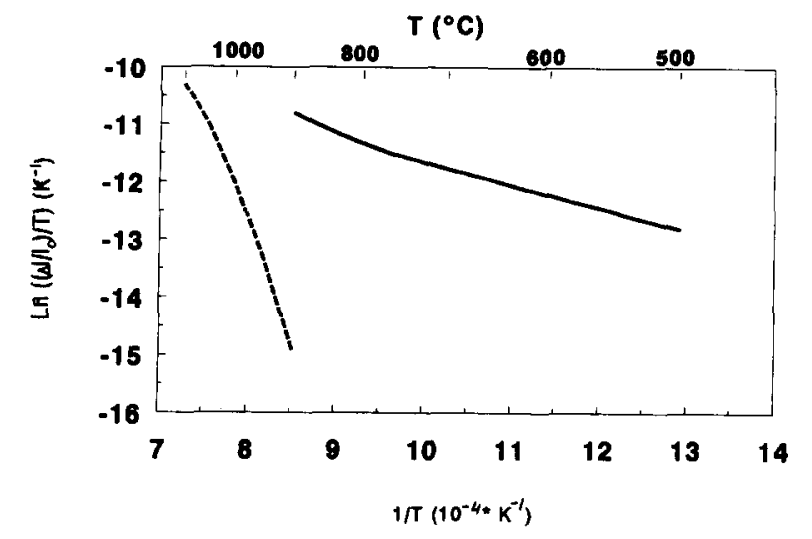

Fig. 3. Arrhenius plots of the initial densification stages for a ZY5.8 ( $\longrightarrow$ ) chloride and (---) Tosoh compact during nonisothermal sintering. Heating rate $2^{\circ} \mathrm{C} / \mathrm{min}$.

ondly, a remarkable difference in densification behaviour is seen in the low-temperature region ranging from 500 to $900^{\circ} \mathrm{C}$. Slight densification can be observed in the case of the chloride compact, whereas the Tosoh compact does not densify at all.

The densification of a powder compact in the initial sintering stage can be described by ${ }^{23}$

$$
\left[\frac{\left(\Delta l / l_{\mathrm{o}}\right)}{T}\right]=\text { const } \exp \left(\frac{-m E_{\mathrm{a}}}{R T}\right)
$$

where $m$ is a constant characteristic for the sinter mechanism, $E_{\mathrm{a}}$ is the apparent activation energy for densification, $\Delta l / l_{\mathrm{o}}$ is the relative shrinkage and $R T$ has its usual meaning.

Linearization of eqn (2) results in

$$
\ln \left[\frac{\left(\Delta l / l_{\mathrm{o}}\right)}{T}\right]=\frac{-m E_{\mathrm{a}}}{R T}+\mathrm{const}
$$

When plotting $\ln \left[\left(\Delta l / l_{\mathrm{o}}\right) / T\right]$ as a function of $1 / T$ a straight line with slope $m E_{\mathrm{a}} / R$ will be obtained when only one single mechanism is operative. In Fig. 3 $\ln \left[\left(\Delta l / l_{\mathrm{o}}\right) / T\right]$ versus $1 / T$ has been plotted for both the chloride and Tosoh compacts. Assuming a certain sinter mechanism, the activation energy can be calculated.

In the case of the chloride compact, four sintering stages were determined. As was discussed before, after compaction at $400 \mathrm{MPa}$ the chloride compact contains small aggregates. ${ }^{21}$ In the first stage $(T<$ $650^{\circ} \mathrm{C}$ ) the microstructure changes completely. The aggregate regions with high packing density and consequently a large number of contact points densify more rapidly than the surrounding matrix, which contains a lower number of contact points per unit volume. ${ }^{12,13,24}$ Densification in this temperature region will therefore be restricted to the internal aggregate structure. In the course of this process, the pore volume within the aggregates will be transported to the surface of the aggregates. This results in a complete densification of the aggregates. Assuming that each aggregate contains 5-6 primary

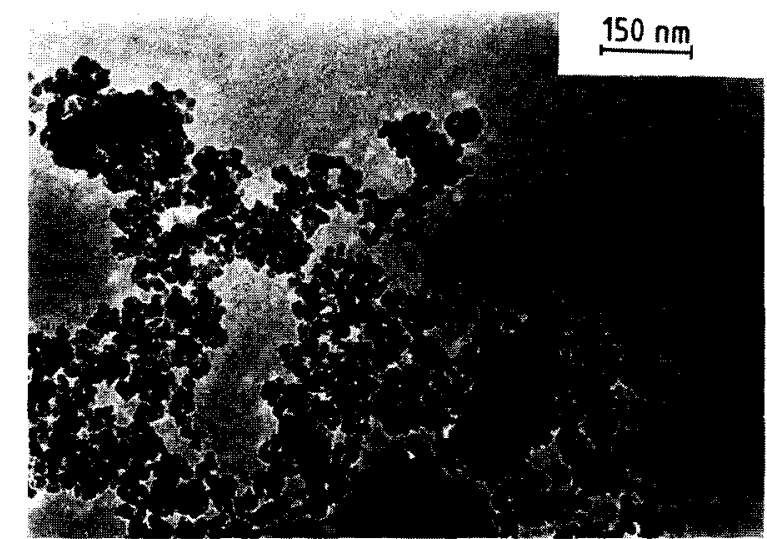

Fig. 4. TEM micrograph of a non-isothermally sintered chloride compact at $750^{\circ} \mathrm{C}$ (stage 2 ).

crystallites the size of a completely densified aggregate would be about 13-14 nm. XRLB (X-ray line broadening) measurements performed on a sample sintered at $650^{\circ} \mathrm{C}$ yielded an average particle size of about $12 \mathrm{~nm}$. The TEM photograph in Fig. 4 shows a particle size of about 13-14 nm when the sample was sintered at a somewhat higher temperature. The agreement seems very reasonable.

Finally, gas adsorption/desorption measurements were used to study the change in pore morphology. Assuming that the (spherical) recrystallized aggregates are arranged in simple cubic arrays (porosity about $50 \%$ ) the radius of a sphere inscribed in the pore $\left(R_{\text {pore }}\right)$ can be calculated using

$$
R_{\text {pore }}=0 \cdot 732 R_{\text {cryst }}
$$

with $R_{\text {cryst }}$ the radius of the densified aggregate. Using eqn (4) and a particle size of $14 \mathrm{~nm}$, an interaggregate pore radius of $5.1 \mathrm{~nm}$ is calculated. Using the adsorption branch of the adsorption/ desorption curve (Fig. 5), the actual measured pore radius at $650^{\circ} \mathrm{C}$ is about $5 \mathrm{~nm}$ (Fig. $6($ a)). This fits reasonably well with the calculated pore radius. From the combination of these measurements it was concluded that the aggregates were completely dense

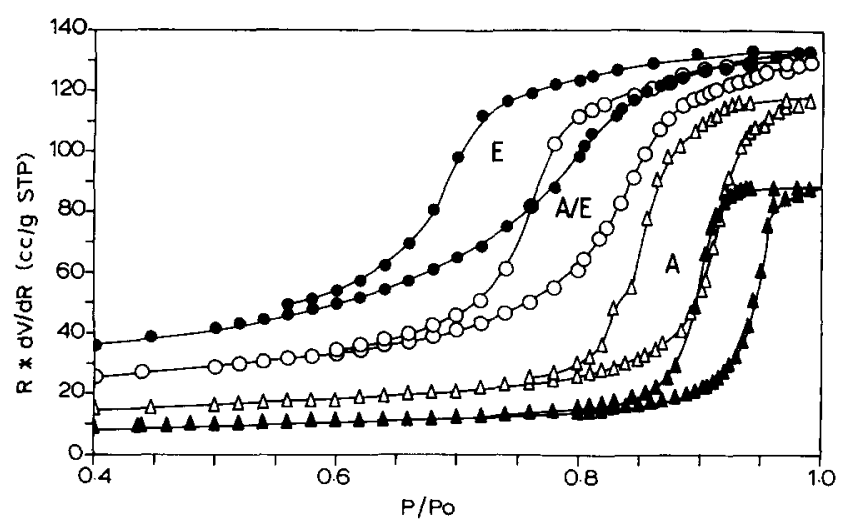

Fig. 5. Adsorption/desorption curves of a chloride green compact $\left(550^{\circ} \mathrm{C}\right)$ and after non-isothermal sintering at $(\mathrm{O})$ $650^{\circ} \mathrm{C},(\triangle) 750^{\circ} \mathrm{C}$ and $(\Delta) 850^{\circ} \mathrm{C}$. The hysteresis changes from $\mathrm{E}$ to A type ${ }^{25}$ with increasing temperature. 


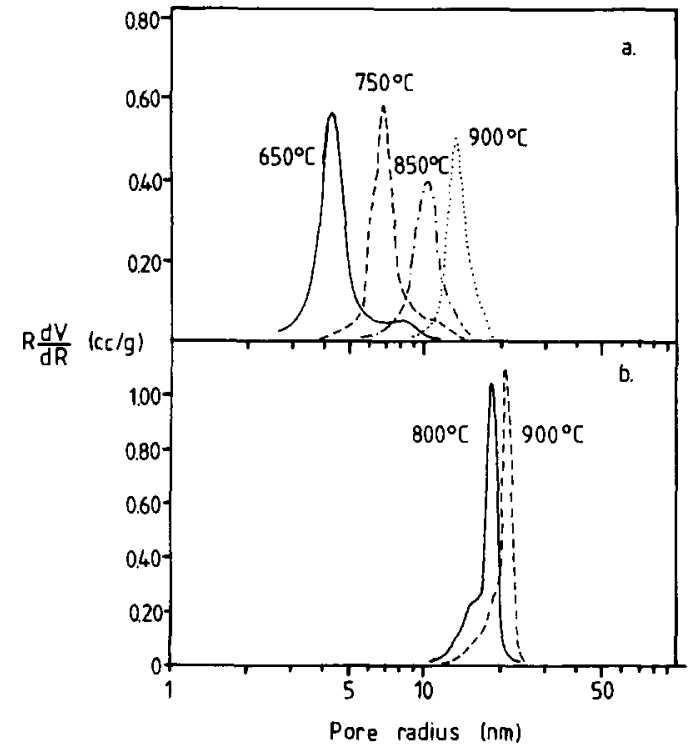

Fig. 6. Pore radius distribution data calculated from the adsorption branch after non-isothermal sintering: (a) chloride: (b) Tosoh.

at the end of this stage, while specifically XRLB leads to the conclusion that the aggregates were transformed into single crystallites.

Although the microstructure has changed severely there is hardly any macroscopic densification in this stage. The presence of the small shoulder with larger pore radius in the samples sintered at 650 and $700^{\circ} \mathrm{C}$ (Fig. 6(a)) might be indicative of remnants of unfractured strong 'agglomerates' which can give rise to microscopic back-stresses.

The second stage in the sintering process ranges from 650 to about $900^{\circ} \mathrm{C}$ (Fig. 2(a)). Here the relative density increases from $48 \%$ to $53 \%$. Although the increase in density is not very large it is significant and can give mechanistic information.

Assuming that $m=1 / 3$ in eqn (3) (grain boundary diffusion), $E=100 \pm 10 \mathrm{~kJ} / \mathrm{mol}$. As the Arrhenius plot is not completely linear the presence of another densification mechanism besides grain boundary diffusion is indicated. The activation energy (100 $\mathrm{kJ} / \mathrm{mol}$ ) is too small to be correlated to any known diffusional mechanism. Furthermore, it cannot be compared with literature values because, to the authors' knowledge, no data are available about such fine-grained (porous) systems at these temperatures. Nevertheless, it seems that surface diffusionassisted grain boundary slip plays an important role. This is supported by the consideration that a large part of the ions is present in the surface or grain boundary region and that the ratio of free surface/ grain boundary is relatively high, which promotes the possibility of reorganization processes like grain boundary slip. Although the increase in density might be small, intercrystallite sintering processes (neck formation and growth) occur. With increasing temperature the pore size distribution becomes more unimodal (Fig. 6(a)) and the hysteresis loop changes from A/E type to A type (Fig. 5). ${ }^{25}$ So with increasing temperature the pore shape changes from spheroidal cavities between close-packed (spherical) particles into more cylindrically shaped pores. This corresponds to an increase in the total neck surface area. The percentage neck surface area $\left(=\left(S_{\text {geo }}-S_{\mathrm{BET}}\right) /\right.$ $S_{\mathrm{BET}}$, with $S_{\text {geo }}$ the geometrical surface area) can be estimated from a correlation between neck area and inaccessible surface area. ${ }^{26} \mathrm{~A}$ calculation shows that the percentage neck area increases from $15 \%$ at $650^{\circ} \mathrm{C}$ to $56 \%$ at $850^{\circ} \mathrm{C}$. Detailed analyses have been performed by Mercera et al. ${ }^{17}$ and Boutz et al. ${ }^{27}$ Surface diffusion is probably responsible for the observed neck growth. However, surface diffusion does not contribute to densification. Although grain boundary diffusion might contribute to densification it is expected that the densification is mainly caused by a reorganization process with the sintering stress as the driving force, which results, owing to grain boundary slip, in viscous or plastic deformation. Grain boundary slip can be expected in the case of large porosity, small grain size and small activation energy. ${ }^{15,28-31}$ So it is concluded that grain boundary slip is the main mechanism responsible for this reorganization process.

A combination of particle reorganization and grain growth is very important. It may influence the pore coordination in such a way that the pore becomes susceptible to removal. ${ }^{32}$

Large sintering stresses, expressed as the change in surface energy per unit of volume, develop as a result of the small pore curvatures and crystallite sizes. The sintering stress $(P)$ can be expressed as ${ }^{33}$

$$
P=\frac{2 \gamma_{\mathrm{b}}}{D}+\frac{2 \gamma}{ \pm r}
$$

where $\gamma_{b}$ is the grain boundary energy, $\gamma$ the free surface energy, $D$ the particle diameter and $r$ the radius of the pore curvature. At a temperature of $900^{\circ} \mathrm{C}$ this yields a sintering stress of about $70 \mathrm{MPa}$. External stresses of this order of magnitude are also used in superplastic deformation experiments of $\mathrm{Y}$ TZP with relatively large grains. Therefore they seem sufficient to induce local deformation and densification in nanostructured materials.

The third sintering stage ranges from 900 to $1150^{\circ} \mathrm{C}$. In this stage the main part of the densification takes place. The relative density increases from $53 \%$ to $90-95 \%$. In this temperature range grain boundary diffusion, which is a more effective mechanism for densification than volume diffusion, is expected to be the main densification mechanism. This is supported by the fact that there is still a considerable amount of matter present in the grain boundary area even at the end of this stage (about $15 \%$ ). Even in this stage the sintering stress can still be very high. 
In the fourth sintering stage at temperatures above $1150^{\circ} \mathrm{C}$ complete densification takes place to $99 \%$ of the theoretical density (with volume diffusion as the main densification mechanism).

Contrary to the chloride compact, macroscopic densification in the Tosoh compact starts at a temperature of $900^{\circ} \mathrm{C}$ or higher (Figs 2(a) and 3). Although no macroscopic densification takes place below $900^{\circ} \mathrm{C}$ a similar process as in stage 1 of the chloride compact seems to occur. The aggregates (about $50 \mathrm{~nm}$ in size at $500^{\circ} \mathrm{C}^{21}$ ) densify completely between 500 and $900^{\circ} \mathrm{C}$, and finally a single crystal is formed with the size of a densified aggregate by grain growth of the crystallites within the aggregate $(36 \mathrm{~nm}$, see Table 2$)$. Using a simple geometrical relation:

$$
\bar{d}_{\mathrm{T}}=\bar{d}_{\mathrm{aggr}}(1-\varepsilon)^{1 / 3}
$$

where $\bar{d}_{\mathrm{aggr}}$ is the average aggregate size and $\varepsilon$ the porosity, the average particle size $\bar{d}_{\mathrm{T}}$ of the fully densified aggregate is calculated to be $39 \mathrm{~nm}$. This compares well with the measured value. Figure $6(\mathrm{~b})$ shows the disappearance of the fraction pores with smaller pore radius (the 'shoulder') which were ascribed to intra-aggregate porosity. At $900^{\circ} \mathrm{C}$ they have disappeared. The resulting pore radius is in good agreement with the result of Lecloux et al. ${ }^{14}$

The initial sintering stage extends to about $1050^{\circ} \mathrm{C}$ (Fig. 3). Initially surface and grain boundary diffusion are probably the major contributors. Above $1050^{\circ} \mathrm{C}$ volume diffusion becomes more important with increasing grain size. For the initial sintering stage and $m=1 / 3$, an apparent activation energy of $275 \mathrm{~kJ} / \mathrm{mol}$ was calculated. This is comparable to what is usually found in these materials.

Table 2. Grain size evolution in a chloride and Tosoh compact sintered non-isothermally between 900 and $1400^{\circ} \mathrm{C}$ (heating rate $2^{\circ} \mathrm{C} / \mathrm{min}$ )

\begin{tabular}{cccccc}
\hline$T$ & \multicolumn{2}{c}{ Tosoh } & & \multicolumn{2}{c}{ Chloride } \\
\cline { 2 - 3 } \cline { 5 - 6 }$\left({ }^{\circ} \mathrm{C}\right)$ & $\begin{array}{c}G \\
(\mathrm{~nm})\end{array}$ & $\begin{array}{c}\rho_{\mathrm{rel}} \\
(\%)\end{array}$ & & $\begin{array}{c}G \\
(\mathrm{~nm})\end{array}$ & $\begin{array}{c}\rho_{\text {rel }} \\
(\%)\end{array}$ \\
\hline 500 & 27 & 50 & & 8 & 48 \\
550 & $a$ & 50 & & 9 & 48 \\
600 & $a$ & 50 & & 10 & 48 \\
650 & $a$ & 50 & & 12 & 48 \\
700 & 28 & 50 & & 12 & 49 \\
750 & $a$ & 50 & & 15 & 49 \\
800 & 30 & 50 & & 15 & 51 \\
850 & $a$ & 50 & & 19 & 53 \\
900 & 36 & 50 & & 20 & 55 \\
950 & 41 & 50 & & 27 & 58 \\
1000 & 47 & 51 & & 32 & 63 \\
1050 & 56 & 53 & & 38 & 78 \\
1100 & $a$ & 58 & & 75 & 92 \\
1200 & 150 & 76 & & 102 & 95 \\
1300 & $a$ & 97 & & 200 & 97 \\
1400 & 300 & 99 & & 240 & 98 \\
\hline
\end{tabular}

${ }^{a}$ Not measured.
Comparing the powders it is noticed that the activation energy for densification in the initial sintering stage of the chloride compact is considerably lower, resulting in a dense ceramic at lower temperature. As will be shown in the next section this is mainly due to the much smaller primary crystallites and aggregate size in the chloride compact.

\subsection{Non-isothermal grain growth}

Isothermal grain growth behaviour can be described with kinetic growth equations of the general form ${ }^{34}$

$$
G^{n}-G_{\mathrm{o}}^{n}=k t
$$

with $n$ a constant characteristic for a given grain growth mechanism, $G$ and $G_{\text {o }}$ the actual size and starting grain size for a certain grain growth stage, respectively, $k$ a kinetic constant and $t$ the time. After linearization and use of the Arrhenius equation for $k$ $\left(k=k_{\mathrm{o}}^{*} \exp (-Q / R T)\right)$, eqn (8) is obtained for nonisothermal grain growth with constant heating rate: ${ }^{35}$

$$
\ln \left(G^{n}-G_{\mathrm{o}}^{n}\right) \simeq-\frac{Q}{R T}+\ln (T)+C
$$

with $Q$ the apparent activation energy for grain growth and $C$ a constant independent of temperature. The value of $n$ was obtained from an Arrhenius plot, using eqn (8), by a least squares fit. Using this $n$ value an apparent activation energy could be calculated from the slope of the Arrhenius plot. For $G_{\mathrm{o}}$ the grain size obtained at the end of every previous sintering stage is taken. Grain size evolution during non-isothermal sintering is given in Table 2.

For the chloride powder the grain size data in the first sintering stage are not accurate enough in order to calculate an activation energy. In the second sintering stage for $G_{\mathrm{o}}$ a value of $13 \mathrm{~nm}$ is taken (densified aggregate). At the end of this stage the average grain size is $20 \mathrm{~nm}$. With $n=2$ a value of $Q=$ $94 \pm 18 \mathrm{~kJ} / \mathrm{mol}$ is calculated. The difference in regression coefficients for the various $n$ values was not significantly enough to decide on a particular grain growth mechanism. However, values of $n=1$ (anomalous grain growth) and $n=4$ (pore dragcontrolled grain growth) are not very likely, because of the rather narrow grain size distribution and the large fraction of open porosity, respectively. Anomalous grain growth can be expected when $G>2 \bar{G}$ $(\bar{G}=$ average grain size $) .{ }^{34}$ XRLB measurements, using the Voight analysis, ${ }^{19}$ were performed on a compact sintered at $750^{\circ} \mathrm{C}$ to check the grain size distribution (and so the absence of anomalous grain growth). The grain size ranged from 12 to $23 \mathrm{~nm}$, with an average grain size of $15 \mathrm{~nm}$. As large crystallites are not taken into account in this measurement, TEM photographs were taken to 
confirm the absence of crystallites larger than $25 \mathrm{~nm}$. Such crystallites were not found (Fig. 4). As no solidsolution drag-controlled grain growth $(n=3)$ is expected, normal grain growth $(n=2)$ is the most probable growth mechanism.

In previous work ${ }^{5} \ln (T)$ on the right side of eqn (8) was subtracted instead of added. To evaluate this effect $Q$ was also calculated according to the equation used by van de Graaf. For the second sintering stage this equation yields $112 \mathrm{~kJ} / \mathrm{mol}$ instead of the $94 \mathrm{~kJ} / \mathrm{mol}$ calculated in the present study. Although the equation used by van de Graaf $e t$ al. ${ }^{5}$ yields somewhat higher values than the present ones they are still low compared to literature values. The low apparent activation energies for grain growth and densification indicate a very large reactivity. This is supported by work of Birringer et $a l^{36}$ on nanoscale $\mathrm{TiO}_{2}$, where an extreme reactivity was found owing to strongly enhanced grain boundary diffusion.

In the third sintering stage the average grain size increased to about $75 \mathrm{~nm}$ at $1100^{\circ} \mathrm{C}$. Between 900 and $1050^{\circ} \mathrm{C}$ the grain growth rate is relatively slow (Table 2). Above $1050^{\circ} \mathrm{C}$ the grain growth rate increases, indicating the presence of another grain growth stage. This is probably due to a rapid increase in relative density (Table 2). As eqns (7) and (8) are only valid for non-densifying systems, no activation energy can be calculated, although a statement about the grain growth mechanism can be made. Based on XRLB measurements, performed on a specimen sintered at $1000^{\circ} \mathrm{C}, n=1$ (anomalous grain growth) was rejected. The grain size ranged from 15 to $40 \mathrm{~nm}$, with an average of $32 \mathrm{~nm}$. TEM micrographs supported the absence of much larger grains. Although a decision between the other three grain growth constants cannot really be made, it is expected that the grain growth starts normal $(n=2)$ and will become solid-solution drag-controlled with increasing grain size $(n=3)$. Evidence for this point of view can be found in Ref. 37, and in Section 3.4. The retarding effect of the solid-solution drag is discussed in Refs 7 and 21.

In the final sintering stage the grain size increases to about $0.24 \mu \mathrm{m}$ at $1400^{\circ} \mathrm{C}$ (Table 2). It is important to note that a nearly dense specimen $(96 \%)$ is obtained after non-isothermal sintering to $1200^{\circ} \mathrm{C}$. In this case the grain size is as small as $0.1 \mu \mathrm{m}$, which potentially makes it an interesting material for hotforging (superplastic) deformation experiments.

Concerning grain growth in Tosoh compacts a similar qualitative picture as for the chloride compact is obtained, although the temperatures are much higher. The grain sizes at various temperatures are listed in Table 2. Slow grain growth is observed up to $900^{\circ} \mathrm{C}$. At this temperature, where macroscopic densification starts, the grain size is about
$36 \mathrm{~nm}$. This is the size of a completely densified aggregate (see Section 3.2). Therefore it is reasonable to suggest that also in this case densification and recrystallization of the aggregates to new secondary particles take place. In the sintering stage below $900^{\circ} \mathrm{C} Q=101 \pm 12 \mathrm{~kJ} / \mathrm{mol}(n=2)$, which is reasonably consistent with the $Q$ values of the chloride compact in the same temperature region, whereas overall densification has already started in the chloride compact. For the temperature region 900 $1050^{\circ} \mathrm{C}, Q=200 \pm 16 \mathrm{~kJ} / \mathrm{mol}(n=2)$. At $T>1050^{\circ} \mathrm{C}$ it is expected that fast but normal grain growth takes place to an average grain size of about $0.15 \mu \mathrm{m}$ at $1200^{\circ} \mathrm{C}$, which is larger than in the chloride compact (Table 2).

It has become clear that it is very important to synthesize powders with small aggregates, since this will decrease the value of $G_{0}$. This value is important for several reasons: (i) it determines the minimum grain size in the sintered compact where overall densification starts; (ii) the smaller the $G_{\mathrm{o}}$, the more sinter active the powder will be; this means that the sinter temperature can be much lower with a smaller resulting final grain size; (iii) the size of $G_{\mathrm{o}}$ determines the size of the smallest cracks developed during the reorganization process which takes place when the aggregates densify. Smaller grains produce smaller cracks, which may finally improve both strength and Weibull modulus under ideal conditions.

\subsection{Isothermal sintering}

In order to obtain dense ceramics with small grain sizes during isothermal sintering proper sintering temperatures must be chosen. The best temperature is situated in the third stage of the non-isothermal sintering process because major densification takes place there. Therefore temperatures of 1000 and $1050^{\circ} \mathrm{C}$ were chosen.

\subsubsection{Sintering at $1000^{\circ} \mathrm{C}$}

The isothermal sintering curve of the samples sintered at $1000^{\circ} \mathrm{C}$ is shown in Fig. 7. Starting with a relative density of $63 \%$, a relative density of more than $95 \%$ is obtained after $100 \mathrm{~h}$. At this point the grain size is approximately $80 \mathrm{~nm}$. Relative densities of more than $97 \%$ are obtained after $270 \mathrm{~h}$. In this case the grain size is still below $0.1 \mu \mathrm{m}$ (Fig. 7). The grain growth kinetics in the high density area $(>92 \%)$ are best fitted with $n=3$ (eqn (7)). This grain growth constant significantly gave the highest regression coefficient. Using the pre-exponential factor calculated from the grain growth data of Nieh $\&$ Wadsworth ${ }^{38}\left(k_{\mathrm{o}}=7.23 \times 10^{-7} \mathrm{~m}^{3} / \mathrm{s}\right.$ for $\left.n=3\right)$, $Q=516 \pm 24 \mathrm{~kJ} / \mathrm{mol}$. This is lower than the value of $580 \mathrm{~kJ} / \mathrm{mol}$ obtained by Nieh \& Wadsworth ${ }^{38}$ for a ZY 5.8 material sintered at $1400^{\circ} \mathrm{C}$ with an initial average grain size of $0.3 \mu \mathrm{m}$. Because both systems 


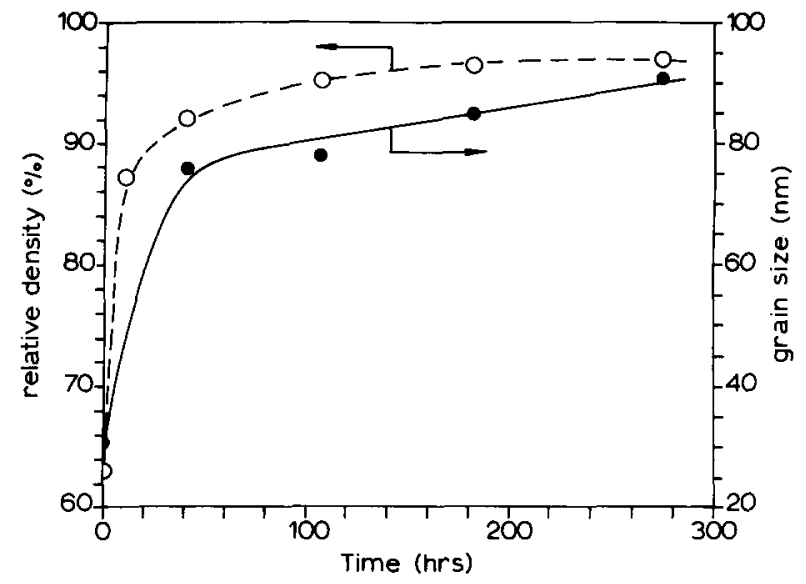

Fig. 7. (O) Relative density and (O) grain size evolution of a chloride compact sintered isothermally at $1000^{\circ} \mathrm{C}$.

are best fitted with the same grain growth mechanism, this again points to the advantage which can be gained when using finer-grained systems (i.e. lower sintering temperature and/or shorter sintering times).

\subsubsection{Sintering at $1050^{\circ} \mathrm{C}$}

The isothermal sintering results for the samples sintered at $T=1050^{\circ} \mathrm{C}$ are shown in Fig. 8, where both grain size and relative density are plotted as a function of the sintering time. Two densification stages are distinguished: (i) sintering times shorter than $7 \mathrm{~h}$ and (ii) longer sintering times.

In the first stage the relative density increases from $78 \%$ to $96 \%$. Because of the small grain size, grain boundary diffusion will be the most important densification mechanism. In this stage the grain size increased from 38 to $60 \mathrm{~nm}$.

In the second stage the average grain size increased to $125 \mathrm{~nm}$ after $70 \mathrm{~h}$ of sintering. The grain growth data in this stage are best fitted with $n=3$, suggesting a solid-solution drag-controlled grain growth. $Q=505 \pm 27 \mathrm{~kJ} / \mathrm{mol}$ when using the same $k_{\mathrm{o}}$

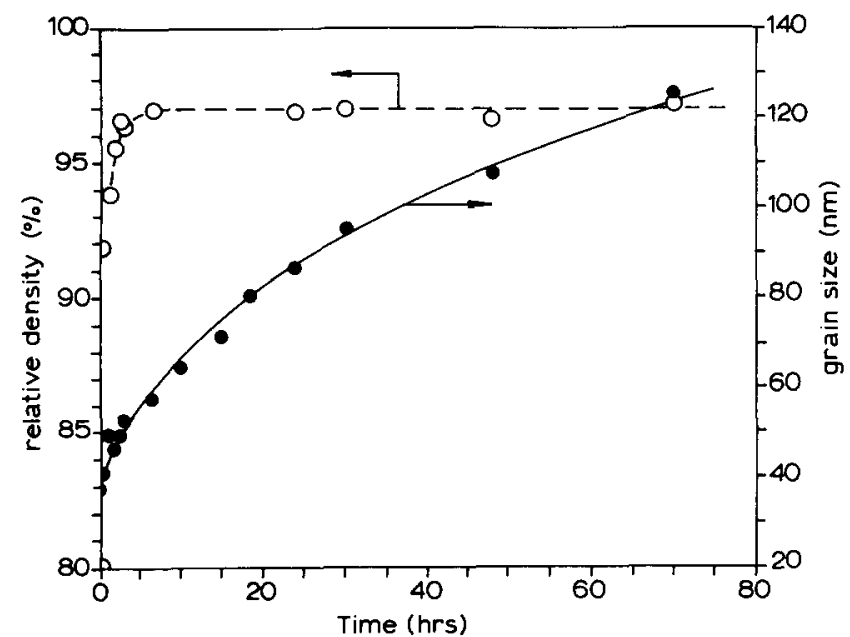

Fig. 8. (O) Relative density and (O) grain size evolution of a chloride compact sintered isothermally at $1050^{\circ} \mathrm{C}$.

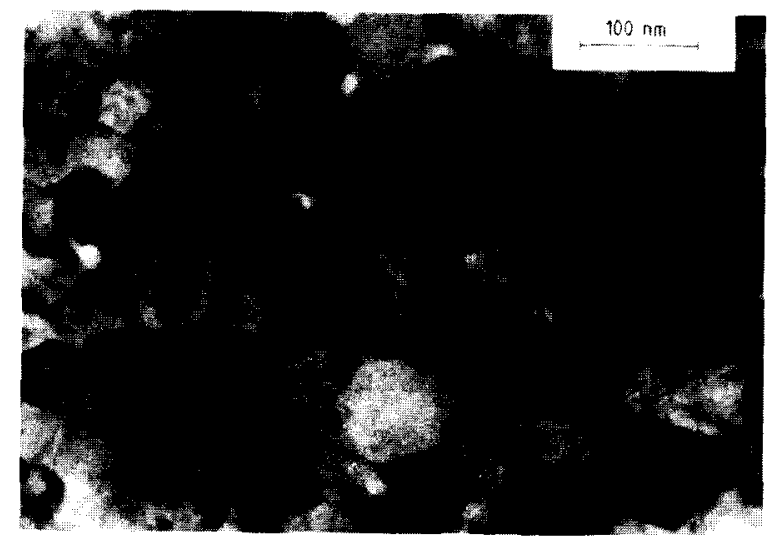

Fig. 9. TEM micrograph of a chloride compact sintered isothermally at $1050^{\circ} \mathrm{C}$ for $6 \cdot 5 \mathrm{~h} . \rho_{\text {rel }}=97 \%$.

value as before. This is comparable with the $Q$ value at $1000^{\circ} \mathrm{C}$. The most important feature of this experiment is that after $7 \mathrm{~h}$ of sintering at a very low temperature a ceramic is obtained with a grain size in the nanoscale range $(60 \mathrm{~nm}$, Fig. 9). The exact mechanism of grain growth is discussed in Ref. 21 , where the grain growth is described as a function of the yttria percentage and in terms of retarded grain growth (drag mechanism).

Unfortunately, the isothermal sintering results were not very reproducible. In general, the grain size was reproducible but there was some scatter in the relative density $(85-95 \%)$. This was believed to be a consequence of the compaction process in which powders were used which were not granulated and which showed bad flowability. Therefore improvement of the compaction process is a topic of recent research. Some results are given in Ref. 21.

A comparison of densification and grain growth mechanisms between isothermal and nonisothermal sintering is not possible because of the fact that the non-isothermal analysis refers to the initial sintering stages while the isothermal analysis refers to the final sintering stages.

\section{Conclusions}

Ultra-fine-grained and highly reactive Y-TZP powders can be prepared by the chloride synthesis. The powders contain very small aggregates with a size of about $16 \mathrm{~nm}$ built up from primary crystallites with a size of $8 \mathrm{~nm}$.

Because of these small aggregates and the slow grain growth in the final densification stages, dense ceramics with grain sizes in the nanoscale range could be obtained. Dense ceramics with grain sizes of only 80 and $60 \mathrm{~nm}$ were obtained after 100 and $7 \mathrm{~h}$ of isothermal sintering at 1000 and $1050^{\circ} \mathrm{C}$, respectively.

During non-isothermal sintering of the chloride compact four stages were distinguished: 
(i) Densification of the aggregates to single crystallites at temperatures below $650^{\circ} \mathrm{C}$.

(ii) Slight densification and slow (normal) grain growth between 650 and $900^{\circ} \mathrm{C}$. Grain boundary slip and grain boundary diffusion presumably are the main densification mechanisms.

(iii) Densification to a relative density of $95 \%$ between 900 and $1150^{\circ} \mathrm{C}$. Grain growth seems to start normal and changes to solidsolution drag-controlled at higher temperatures (owing to segregation of yttrium).

(iv) Further densification and grain growth with volume diffusion as the most important mechanism at temperatures above $1150^{\circ} \mathrm{C}$.

The activation energies for grain growth and densification of the Tosoh powders (which are in accordance with other literature values) are considerably higher than those of the chloride powders. This is mainly due to the larger aggregate size compared to the aggregate size in the chloride powders.

The isothermal grain growth data $(T=1000$ and $1050^{\circ} \mathrm{C}$ ) for the chloride powders are best fitted with $n=3$, giving an apparent activation energy of about $510 \pm 25 \mathrm{~kJ} / \mathrm{mol}$ in both cases, which indicates the presence of a solid-solution drag-controlled grain growth mechanism. This is again rather low compared with literature data and partly explains the good reactivity of these powders.

\section{Acknowledgement}

This research was partly supported by the Innovative Research Program on Technical Ceramics (IOPTK) with financial aid from the Dutch Ministry of Economic Affairs.

\section{References}

1. Claussen, N., Microstructural design of zirconia-toughened ceramics (ZTC). In Advances in Ceramics, Vol. I2, Science and Technology of Zirconia II, ed. N. Claussen, M. Rühle \& A.H. Heuer. The American Ceramic Society, Inc., Columbus, Ohio, 1984, pp. 325-51.

2. Lange, F. F., Transformation-toughened $\mathrm{ZrO}_{2}$ : Correlations between grain size control and composition in the system $\mathrm{ZrO}_{2}-\mathrm{Y}_{2} \mathrm{O}_{3}$. J. Mater. Sci., 17 (1982) 240-2.

3. Winnubst, A. J. A. \& Burggraaf, A. J., The aging behavior of ultrafine-grained Y-TZP in hot water. In Advances in Ceramics, Vol. 24A, Science and Technology of Zirconia III, ed. S. Somiya, N. Yamamoto \& H. Yanagida. The American Ceramic Society, Inc., Columbus, Ohio, 1989, pp. 39-47.

4. Sato, T. \& Shimada, S., Transformation of yttria-doped tetragonal $\mathrm{ZrO}_{2}$ polycrystals by annealing in water. $J . A m$. Ceram. Soc., 68 (1985) 356-9.

5. van de Graaf, M. A. C. G., ter Maat, J. H. H. \& Burggraaf, A. $\mathrm{J}$., Microstructure and sintering kinetics of highly reactive $\mathrm{ZrO}_{2}-\mathrm{Y}_{2} \mathrm{O}_{3}$ ceramics. J. Mater. Sci., 20 (1985) 1407-18.

6. Rhodes, W. H., Agglomerate and particle size effects on sintering yttria-stabilized zirconia. J. Am. Ceram. Soc., 64 (1981) 19-22.

7. Winnubst, A. J. A., Theunissen, G. S. A. M., Groot Zevert, W. F. M. \& Burggraaf, A. J., The sintering behaviour of finegrained $\mathrm{ZrO}_{2}-\mathrm{Y}_{2} \mathrm{O}_{3}$ ceramics. In Science of Ceramics 14, ed. D. Taylor. The Institute of Ceramics, Shelton, Stoke-onTrent, Staffs, UK, 1988, pp. 309-14.

8. Groot Zevert, W. F. M., Winnubst, A. J. A., Theunissen, G. S. A. M. \& Burggraaf, A. J., Powder preparation and compaction behaviour of fine-grained Y-TZP. J. Mater. Sci., 25 (1990) 3449-55.

9. van de Graaf, M. A. C. G. \& Burggraaf, A. J., The wetchemical preparation of zirconia powders; Their microstructure and behaviour. In Advances in Ceramics, Vol. 12, Science and Technology of Zirconia II, ed. N. Claussen, M. Rühle \& A. H. Heuer. The American Ceramic Society, Inc., Columbus, Ohio, 1984, pp. 744-65.

10. Pampuch, R. \& Haberko, K., Agglomerates in ceramic micropowders and their behaviour on cold pressing and sintering. Mat. Sci. Mon., 16 (1983) 623-34.

11. Kosmac, T., Krasevec, V., Gopalakrishnan, R. \& Kosmac, M., Crystallization of $\mathrm{ZrO}_{2}$ from amorphous precipitates and its influence on the microstructure of sintered ceramics In Advances in Ceramics, Vol. 24A, Science and Technology of Zirconia III, ed. S. Somiya, N. Yamamoto \& H. Yanagida. The American Ceramic Society, Inc., Columbus, Ohio, 1988, pp. 167-72.

12. Kellett, B. \& Lange, F. F., Stresses induced by differential sintering in powder compacts. J. Am. Ceram. Soc., 67 (1984) 369.

13. Dynys, W. F. \& Halloran, J. W., Influence of aggregates on sintering. J. Am. Ceram. Soc., 67 (1984) 596-601.

14. Lecloux, A. J., Verleye, P., Bronckart, J., Noville, F., Marchot, P. \& Pirard, J. P., Texture and sintering of zirconium dioxide-yttrium oxide ceramics. Reactivity of Solids, 4 (1988) 309-25.

15. Wakai, F. \& Nagono, T., The role of interface-controlled diffusion creep on superplasticity of yttria-stabilized tetragonal $\mathrm{ZrO}_{2}$ polycrystals. J. Mater. Sci. Lett., 7 (1988) $607-9$.

16. Theunissen, G. S. A. M., Bouma, J. S., Winnubst, A. J. A. \& Burggraaf, A. J., Mechanical properties of ultra-fine grained Y-TZP ceramics. J. Mater. Sci., 27 (1992) 4429-38.

17. Mercera, P. D. L., van Ommen, J. G., Doesburg, E. B. M., Burggraal, A. J. \& Ross, J. R. H., Zirconia as a support for catalysts: Evolution of the texture on calcination in air. Applied Catalysis, 57 (1990) 127-48.

18. Dollimore, D. \& Heal, G. R., An improved method for the calcination of pore size distribution from adsorption data. $J$. Appl. Chem., 14 (1964) 109-14.

19. Klug, K. P. \& Alexander, L. E., X-Ray Diffraction Procedures. John Wiley and Sons, New York, 1974.

20. Oel, H. J., Determination of the size distribution of particles, crystallites and pores. Ber. Dtsch. Keram. Ges., 43 (1966) 624-31.

21. Theunissen, G. S. A. M., Microstructure, fracture toughness and strength of (ultra)fine-grained tetragonal zirconia ceramics. PhD thesis, University of Twente, Enschede, The Netherlands, 1991.

22. Winnubst, A. J. A., Theunissen, G. S. A. M. \& Burggraaf, A. J., Compaction and sintering behaviour of nanocrystalline Y-TZP. In Euro-Ceramics, Vol. 1: Processing of Ceramics, ed. G. de With, R. A. Terpstra \& R. Metselaar. Elsevier Applied Science, London, 1990, pp. 393-7.

23. Young, W. S. \& Cutler, I. B., Initial sintering with constant rates of heating. J. Am. Ceram. Soc., 53 (1970) 659-63.

24. van de Graaf, M. A. C. G., van Dijk, T., de Jongh, M. A. \& Burggraaf, A. J., High sinter reactivity and microstructure of fine-grained substituted $\mathrm{ZrO}_{2}$ compacts. In Science of Ceramics 9, ed. K. J. de Vries. Dutch Ceramic Society, 1977 , pp. $75-83$.

25. Zlotnick, J., Determination of pore size distribution in catalysts. Part 1: General review and underlying theory. Chemsa (1981) 146-51. 
26. German, R. M. \& Munir, Z. A., Surface area reduction during isothermal sintering. J. Am. Ceram. Soc., 59 (1976) 379-83.

27. Boutz, M. M. R., Theunissen, G. S. A. M., Winnubst, A. J. A. \& Burggraaf, A. J., Grain growth during sintering of nanocrystalline $\mathrm{Y}$ - and/or Ce-doped tetragonal zirconia. In Superplasticity in Metals, Ceramics and Intermetallics, ed. M.J. Mayo, J. Wadsworth \& M. Kobayashi. MRS, Pittsburgh, Pennsylvania, 1990, pp. 87-92.

28. Panda, P. C., Wang, J. \& Raj, R., Sinter-forging characteristics of fine-grained zirconia. J. Am. Ceram. Soc., 71 (1988) C-507-C-509.

29. Hart, J. L. \& Chaklader, A. C. D., Superplasticity in pure $\mathrm{ZrO}_{2}$. Mat. Res. Bull., 2 (1967) 521-6.

30. Ashby, M. F. \& Verrall, R. A., Diffusion-accommodated flow and superplasticity. Acta Metall., 21 (1973) 149-63.

31. Nieh, T. G., McNally, C. N. \& Wadsworth, J., Superplastic properties of a fine-grained yttria-stabilized tetragonal polycrystal of zirconia. Scripta Metall., 22 (1988) 1297-300.

32. Lange, F. F., Sinterability of agglomerated powders. J. Am. Ceram. Soc., 67 (1984) 83-9.

33. Raj, R., Analysis of the sintering pressure. J. Am. Ceram. Soc., 70 (1987) C-210-C-211.

34. Brook, R. J., Controlled grain growth. In Treatise of Materials Science and Technology, Vol.9, ed. F. F. Y. Wang. Academic Press, New York, 1976, pp. 331-64.

35. Boutz, M. M. R., Ph.D thesis. University of Twente, Enschede, The Netherlands, 1993.

36. Birringer, R., Herr, U. \& Gleiter, H., Trans. Jap. Inst. Metall. Suppl., 27 (1986) 43.

37. Theunissen, G. S. A. M., Winnubst, A. J. A. \& Burggraaf, A. J., Segregation aspects in the $\mathrm{ZrO}_{2}-\mathrm{Y}_{2} \mathrm{O}_{3}$ ceramic system. J. Mater. Sci. Lett., 8 (1989) 55-7.

38. Nieh, T-G. \& Wadsworth, J., Dynamic grain growth during superplastic deformation of yttria-stabilized tetragonal zirconia polycrystals. J. Am. Ceram. Soc., 72 (1989) 1469-72. 